\title{
Biodiesel Production through Catalytic Microwave In-Situ Transesterification of Microalgae (Chlorella sp.)
}

\author{
Mahfud Mahfuda ${ }^{*}$, Ummu Kalsum ${ }^{\mathrm{b}}$, and Viqhi Aswie ${ }^{\mathrm{a}}$ \\ a Chemical Engineering Department, Institut Teknologi Sepuluh Nopember, Surabaya 60111, Indonesia \\ ${ }^{b}$ Chemical Engineering Department, Universitas Muslim Indonesia, Makassar 90231, Indonesia
}

\begin{abstract}
Aim of this research are to study and develop research related to the potential of Chlorella sp. into biodiesel with the help of microwaves in-situ transesterification by characterizing parameters such as microwave power $(300 ; 450 ; 600 \mathrm{~W})$ and reaction time (10; 30; 50 minutes) with catalyst concentration of $\mathrm{KOH}$ and molar ratio of microalga : methanol are $2 \%$ and 1:12 respectively and optimized by response surface methodology with Face Centered Central Composite Design (FCCCD). The study was carried out by dissolving the catalyst into methanol according to the variable which was then put into a reactor containing microalgae powder in the microwave and turned on according to the predetermined variable. After the reaction process is complete, the mixture is filtered and resuspended with methanol for 10 minutes to remove the remaining FAME and then the obtained filtrate is cooled. Water is added to the filtrate solution to facilitate the separation of hydrophilic components before being separated and pushed apart until 3 layers are formed. Amount of FAMEs in the first layer formed were extracted with $n$-hexane solution and washed with water and the FAME product obtained was then distilled to remove the remaining $\mathrm{n}$ hexane and then weighed. The results indicated that yield increased with increasing reaction time and microwave power with the best conditions of 50 minutes each and 440.53 watts with the highest yield reaching $35.72 \%$ (dry basis) through using of $\mathrm{KOH}$ catalysts with low concentrations, 2\%. C2020. CBIORE-IJRED. All rights reserved
\end{abstract}

Keywords: Biodiesel, Chlorella sp., In-situ Transesterification, Microalgae, Microwave

Article History: Received: Oct 30, 2019; Revised: December 28, 2019; Accepted: January 10, 2020; Available online: February 15, 2020 How to Cite This Article: Mahfud, M., Kalsum, U. and Aswie, V. (2020) Biodiesel Production through Catalytic Microwave In-situ Transesterification of Microalgae (Chlorella sp.). International Journal of Renewable Energy Development, 9(1), 113-117. https://doi.org/10.14710/ijred.9.1.113-117

\section{Introduction}

Data from the National Energy Council (DEN) shows that between 2006 and 2030 the world's energy demand increased by $45 \%$ and this was not offset by the availability of increasingly depleted fossil fuels coupled with developing crisis issues on environmental and energy issues which resulted in many researchers have developed sustainable renewable energy (Bahadar and Bilal Khan, 2013). The effort that has been made by Indonesia is to increase the development of new renewable energy such as biofuel. Regarding the development of biomass technology, BPPT has succeeded in developing first and second generation biodiesel derived from vegetable oils such as palm oil (first generation) and agricultural and forestry processing wastes such as oil palm empty fruit bunches and rice husk (second generation). Biodiesel is chosen because it is a new alternative to replace fuel that is more environmentally friendly.

However, the development of first generation biodiesel is less effective because the prices are relatively cheaper than the raw materials and raw materials based on food ingredients will result in competition between energy and food needs which causes large land requirements. While the second generation has a weakness because it requires a long time in preparing the raw material.

Therefore, it is necessary to develop fuels that weigh the concept of environmentally sustainable development. Microalgae is a third generation biodiesel feedstock (there is no competition between the food and energy sectors) which is now being researched because of the potential to be developed. Approximately, 1.46 x 1011 tons of biomass is produced throughout the world through photosynthesis, including $40 \%$ for microalgae photosynthesis. The quantum efficiency of microalgae in converting solar energy into biomass ranges from $2-10 \%$ compared to terrestrial plants which are less than $1 \%$. Plus, the growth rate is very high up to 1-3 times per day (Ananyev, Carrieri and Dismukes, 2008). and the oil productivity of microalgae is much higher when compared to palm oil for the same land area which can reach 20 times (Khan et al., 2009).

One type of microalgae that can produce lipid products is Chlorella sp. Compared to other types of microalgae, the lipid content of Chlorella sp. quite high at $10-58 \%$ of the dry weight (Chisti, 2007). The two main fatty acid content is palmitic acid (C16: 0) which reaches $8.09 \%$ and

\footnotetext{
* Corresponding author: mahfud@chem-eng.its.ac.id
} 
palmitoleic acid (C16: 1) of 2.15\% (Prartono et al., 2010). Biodiesel consists of $\mathrm{C} 12-\mathrm{C} 22$ fatty acids, so that the fatty acid content of Chlorella sp. which is dominated by palmitic acid (C16: 0) and palmitoleic acid (C16: 1) has the potential to produce biodiesel with high yield.

Several methods have been applied in converting biomass to biofuels including biochemical methods (fermentation, transesterification and anaerobic digestion) and thermochemistry (combustion, gasification, liquefaction and pyrolysis). Among several methods of production, transesterification is a popular and more commercial method for producing biodiesel. In addition, this method has been proven successful for several types of feedstock (Akubude, Nwaigwe and Dintwa, 2018). Moreover, its application from microalgae produced by transesterification algal oil and methanol using base or acid catalyst (Kalsum et al., 2018). Dai et al. (2014) conducted a study to compare treatment methods using conventional, ultrasonic and microwave assistance in extracting microalgae lipids. Based on the results of his research, microwave assisted methods have more effective results of up to $18 \%$ compared to conventional and ultrasonic methods which each obtain $14 \%$ and $5 \%$ by weight (Dai et al, 2014). This is because microwave energy can increase temperature optimally, causing cells to be damaged because the internal pressure exceeds the pressure around the cell wall (Mahfud et al., 2018).

Therefore, microwave transesterification needs to be applied. In order to be an effective and efficient method, this research will develop a catalytic microwave in situ transesterification method because the extraction and transesterification process occurs simultaneously so that it can save time and energy. Thus, the purpose of this study was to determine the potential of in situ transesterification with the help of microwaves in generating biodiesel from Chlorella sp., find out the effects of the parameters used as variables and optimize condition of this research using Face Centered Central Composite Design (FCCCD)

Development of the use of energy sources in the in situ transesterification process is carried out by the use of microwave irradiation which is applied to help penetrate the cell wall and supply the energy needed during the transesterification process. Microwave waves can accelerate heating, generate temperature and pressure gradients, help remodel cell walls, increase transfer mass and reaction speed so that the process runs more efficiently and effectively because it can save time and energy.

\section{Materials and Methods}

\subsection{Materials}

The microalgae used is Chlorella sp. powder which is the raw material for making biodiesel and obtained from the Brackish Aquaculture Center (BBAP) in Jepara, Central Java. The catalyst in this study is potassium hydroxide $(\mathrm{KOH})$. In addition, the reagent for transesterification is used methanol obtained from the chemical supplier PROLAB-UN 1230 Brataco Chem brand Made In France with 99\% content and assisted with nhexane solution (96\%) as a solvent and co-solvent in the process.

\subsection{Microwave Apparatus}

The main equipment used in this study was an Electrolux microwave EMM2007X model with a frequency of $2.45 \mathrm{GHz}$ and a maximum power of 800 Watts. The transesterification reaction was carried out in a three neck pumpkin glass reactor equipped with a condenser.

\subsection{Microwave Apparatus}

Parameters in this study included microwave power (300; 450; 600 watts), and reaction time (10; 30; 50 minutes) with molar ratio of Chlorella sp. : methanol and $\mathrm{KOH}$ catalyst as control parameters are $1: 12$ and $2 \%$, respectively in atmospheric pressure conditions. On the other hand, this research was optimized by Design Expert 12 with the design type is Face Centered Central Composite Design (FCCCD) with 3 level for each factor and 3 replications at the center points.

Table 1 .

Factor in the experimental design

\begin{tabular}{lcccc}
\multirow{2}{*}{ Factor } & Unit & Low & $\begin{array}{c}\text { Level } \\
\text { Middle }\end{array}$ & High \\
\cline { 3 - 5 } & & $\mathbf{- 1}$ & $\mathbf{0}$ & $\mathbf{+ 1}$ \\
\hline A: Power & $\mathrm{W}$ & 300 & 450 & 600 \\
B: Time & min & 10 & 30 & 50 \\
\hline
\end{tabular}

\subsection{Yield}

Yield is a measurement that is defined as the ratio of the amount of product (biodiesel) produced to the maximum amount of product produced by raw materials. In conventional biodiesel manufacturing, the yield can be expressed as a comparison of the total amount of biodiesel produced with the amount of lipids / oil processed during the reaction.

$Y$ ield $=\frac{\text { crude product mass } \mathrm{x} \text { purity }}{\text { lipid mass }} \times 100 \%$

\subsection{Experiment Procedure}

The research was carried out by dissolving the catalyst into methanol according to the specified variable and stirring it with a magnetic stirrer. The methanol and catalyst mixture is inserted into the reactor containing 10 gr. of microalgae powder in the microwave and turned on according to the predetermined variable. This process is carried out on all variables of the microalgae-methanol ratio, catalyst concentration and microwave power. After the reaction process is complete, the mixture is filtered using a vacuum filter to separate the filtrate. The mixture was resuspended with methanol for 10 minutes to remove the remaining Free Acid Methyl Ester (FAME) and then the obtained filtrate was cooled. Water is added to the filtrate solution to facilitate the separation of the hydrophilic components before being separated, pushed apart for 3 to 3 layers formed. The number of FAMEs in the first layer formed were extracted 3 times with nhexane solution and washed with water to remove the remaining catalyst and methanol The FAME product obtained was then distilled to remove the remaining hexane and then weighed. The methyl ester product obtained was then determined by the yield and analyzed by Gas Chromatography-Mass Spectroscopy (GC MS). 


\section{Result and Discussion}

\subsection{Catalytic Microwave In-situ Transesterification Optimization}

In situ transesterification of microalgae is a transesterification process that occurs directly (direct transesterification) or simultaneously in producing biodiesel. This process is reported to be superior to twostage transesterification or conventional processes that are more dependent on extraction results with organic solvents with low separation efficiency because of the incomplete extraction process. The ineffective use of solvents, the length of time and the many stages of the process are also things that cause high operational costs and product prices. In this study the transesterification of in situ microalgae in producing biodiesel was studied using a microwave as a reactor and heater. Microwave use is intended to replace ineffective conventional heating systems in terms of energy use and time. Energy efficiency of heating by using microwaves is much smaller when compared to conventional heating (Gude et al., 2013)

\subsection{The Effect of Microalgae and Methanol Ratio on Yield}

The ratio of the amount of methanol and microalgae used in this study has a very significant effect on the insitu transesterification reaction. In this reaction methanol functions as a solvent to extract lipids / microalgae oil (AlAmeri and Al-Zuhair, 2019) and also as a reactant during the transesterification process. The use of large amounts of methanol causes contact between methanol and microalgae to be greater and optimal so that the yield produced is also greater.

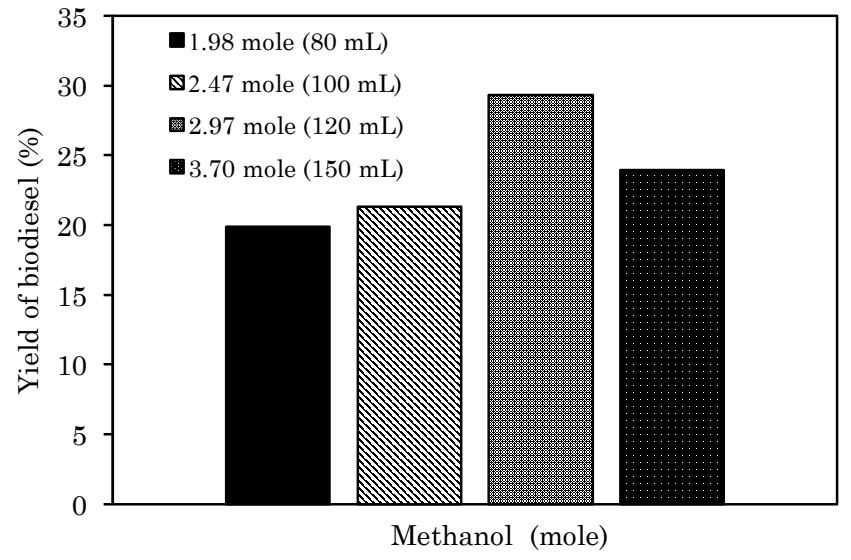

Fig. 1 Yield of Biodiesel on various methanol as a solvent at 450 watt, 30 minutes with $\mathrm{KOH} 2 \%$

Figure 1. shows the use of a $2 \% \mathrm{KOH}$ catalyst at a reaction time of 30 minutes at various methanol to microalgae ratios at $600 \mathrm{watts}$ power. The increase in yield occurred significantly in the use of the ratio of methanol and microalgae $1: 8 ; 1: 10,1: 12$ and $1: 15(\mathrm{w} / \mathrm{v})$. The optimum yield is obtained at a ratio of $1: 12$ which shows that the greater the ratio of methanol and microalgae will increase the yield amount. On the use of methanol with a larger volume the methyl ester yield has decreased (the ratio of methanol and microalgae (w/v) 1:15). This was also reported by Martinez-Guerra et. al, (2014) which stated that the use of a molar ratio above 1: 500 in in-situ transesterification and $2 \% \mathrm{KOH}$ catalyst with microwave irradiation was ineffective and did not show an increase in yield. So in this study using a molar ratio of microalgae to methanol of 1:12.

Transesterification reaction is a reversible reaction that takes place slowly so that the use of excess methanol can accelerate the reaction and shift the reaction right towards the formation of the product. The large amount of methanol causes contact between methanol and microalgae to be greater and the yield produced also becomes larger. The use of excess methanol in the in-situ transesterification reaction causes the capacity of the microwaves absorbed by the material to be greater thereby increasing the excitation of molecules in the material and encouraging an increase in temperature. More volume of methanol can reduce the effect of the catalyst so that microwave irradiation has no effect on microalgae biomass.

\subsection{Analysis of Variance (ANOVA)}

Analysis of variance (ANOVA) of Face Centered Central Composite Design (FCCCD) for response surface quadratic model for the yield of biodiesel is shown in Table 2. ANOVA data shows that the model of this experiment has a significant value which is indicated by $p$-value $0.15 \%$ (below 5\%). This is supported by a large conversion coefficient value, $\mathrm{R}^{2}$ is 0.9619 . In addition The Predicted $\mathrm{R}^{2}$ of 0.7409 is in reasonable agreement with the Adjusted $\mathrm{R}^{2}$ of 0.9239 ; i.e. the difference is less than 0.2. Adeq. precision measures the signal to noise ratio. A ratio greater than 4 is desirable. Your ratio of 15.726 indicates an adequate signal. This model can be used to navigate the design space.

Table 2.

Analysis of variance (ANOVA) for Quadratic Model of Face Centered Central Composite Design (FCCCD)

\begin{tabular}{llllll} 
Source & $\begin{array}{l}\text { Sum of } \\
\text { Squares }\end{array}$ & df & $\begin{array}{l}\text { Mean } \\
\text { Square }\end{array}$ & F-value & $\begin{array}{l}\text { P- } \\
\text { value }\end{array}$ \\
\hline Model & 447.18 & 5 & 89.44 & 25.27 & 0.0015 \\
A-Power & 5.28 & 1 & 5.28 & 1.49 & 0.2762 \\
B-Time & 320.32 & 1 & 320.32 & 90.52 & 0.0005 \\
AB & 0.1089 & 1 & 0.1089 & 0.0308 & 0.8676 \\
$\mathrm{~A}^{2}$ & 95.24 & 1 & 95.24 & 26.91 & 0.0035 \\
$\mathrm{~B}^{2}$ & 5.45 & 1 & 5.45 & 1.54 & 0.2698 \\
Residual & 17.69 & 5 & 3.54 & & \\
Lack of Fit & 17.00 & 3 & 5.67 & 16.27 & 0.0585 \\
Pure Error & 0.6966 & 2 & 0.3483 & & \\
Cor Total & 464.88 & 10 & & & \\
\hline
\end{tabular}

$\mathrm{R}^{2}=96.19 \%, \mathrm{R}^{2}($ pred $)=74.09 \%, \mathrm{R}^{2}(\mathrm{adj})=92.39 \%$, Adeq precision $(15.726)$ $(\mathrm{df}=$ degree of freedom $; \mathrm{F}$-value $=$ value of probability distribution; $\mathrm{p}$-valuse $=$ value of probability $>$ F)

\subsection{The Effect of Micorwave Power and Reaction Time on Yield Biodiesel}

The effect of various microwave power on the catalytic microwave in situ transesterification process of microalgae Chlorella $s p$ was studied at $2 \%$ of $\mathrm{KOH}$ catalysts concentration with varying reaction times of 10 , 30, 50 minutes and microalgae ratio: methanol 1:12 (w/v). The influence of different uses of microwave power in the process of making biodiesel in situ is shown in Figure 2. 

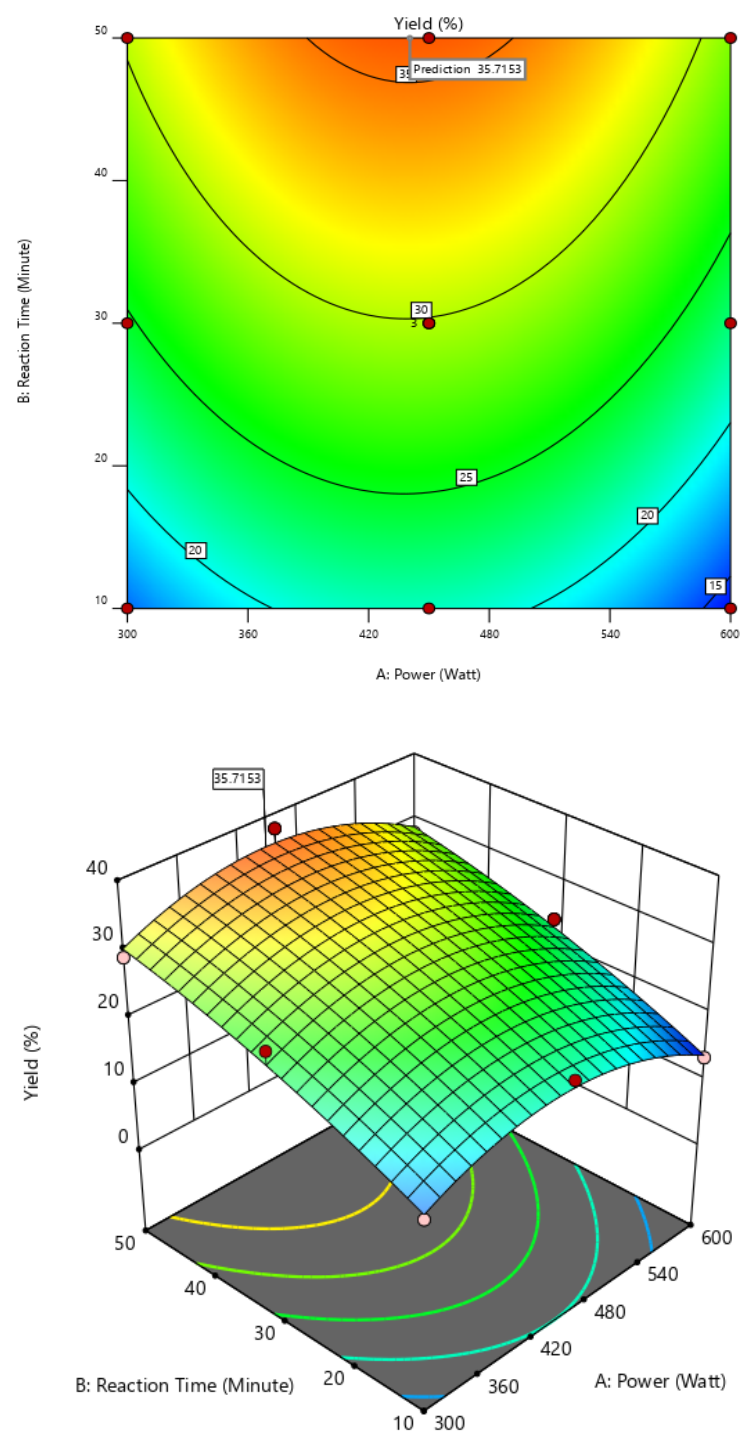

Fig. 2 2D Contour and 3D Graph presenting the effects of microwave power (A) and Reaction Time (B) o the methyl ester of microalgae using catalytic microwave in situ transesterification with FCCCD

Based on the results of research conducted on the insitu transesterification of microalgae with $2 \% \mathrm{KOH}$, the $1: 12 \mathrm{w} / \mathrm{v}$ ratio with different reaction times shows that the increase in power is very influential in the in situ transesterification process. At 300 watts the yield increase significantly occurs from the beginning of the reaction to the reaction time of 50 minutes. In the first 10 minutes the yield FAME obtained was $15.33 \%$ which then increased significantly to $29.09 \%$ in the 50 th minute. This indicates that the use of low power in this process produces maximum interaction in the mixture. so the solvent that evaporates is less. At higher power usage, yield increases occurred until the 40th minute, but decreased after a reaction time of 50 minutes. The optimization with FCCCD shows that maximum yield of $35.72 \%$ at reaction time of 50 minutes on the power at 440.53 Watt and it doesn't happen above 450 watts. In the use of microwaves as heaters, increasing microwave power can cause temperatures to rise and produce high yields or decrease with increasing reaction time. The decrease in the number of yields in the increase in microwave power is caused by the formation of by products of other compounds in microalgae biomass such as di, mono glyceride and glycerol (Martinez-Guerra et al., 2014).

Microwave power and temperature are closely related to in situ transesterification reactions. The incoming power in the microwave affects the amplitude of the wave where the greater the power the greater the electric field produced and the amplitude of the generated microwave will also be greater (Boldor, 2012). The rotational speed of the polar molecule has a linear relationship to the amplitude of the microwave so that the greater the amplitude the faster the polar molecule rotates and the greater the heat generated.

Moreover, the effect of time on the transesterification reaction in situ Chlorella sp. with $\mathrm{KOH}$ catalyst in producing methyl ester can be seen in Fig 2 . In the graph, it can be seen that the transesterification process lasts for 50 minutes. In this process, yield of methyl esters increased significantly to 50 minutes. The effect of the length of reaction time on the increase in yield of methyl esters by using microwave heating is due to the longer contact time causing more damaged cell walls and faster microalgae triglycerides to release enough contact time for the mixture of reactants to form biodiesel (Patil et al., 2011).

The influence of microwave use as a heater in this process was also suggested by Guerra et al. (2013) (Martinez-Guerra and Gude, 2016) which states that microwaves can accelerate organic synthesis with a short reaction time due to an increase in reaction speed as expressed through Arrhenius's law that with increasing reaction time the contact between reactant molecules is increasingly large and product yield formation is likely to increase. But if there has been an equilibrium, increasing time will not affect the product yield.

Catalytic microwave in situ transesterification with $2 \%$ $\mathrm{KOH}$ catalyst, the highest yield of $35.72 \%$ was obtained in the reaction using $2 \% \mathrm{KOH}$ which lasted 50 minutes and microwave power $440.5 \mathrm{~W}$. Trend is shown at 300 watts and 600 watts of power which does not show an increase in yield with increasing reaction time so that it can be stated that the longer reaction time causes the production of biodiesel to be inefficient. Even this is supported by Patil et al (2011) which states that the reaction time is too long resulting in overheating of the reaction resulting in loss of large quantities of solvents, formation by product, and loss of energy in the process.

\subsection{GCMS Analysis for Biodiesel}

Biodiesel is the main product of the microwave using Chlorella sp. Biodiesel yield is in the range of 13.51 $35.08 \%$ of its dry weight. Knowing the composition of biodiesel will help better understand the reactions that occur during the transesterification process and explore its potential use.

The main content of biodiesel from Chlorella $s p$. is methyl ester palmitate as much as $21.04 \%$. The content of methyl ester palmitate is in accordance with the research conducted by Ramesh et al. (2018) which states that the weak acid content of saturated Chlorella sp. Is palmitic acid of $17.12 \%$ which is desired to produce and stability of biodiesel (Ramesh et al., 2018). 


\section{Conclusion}

Microwave use in converting biomass Chlorella $s p$. being biodiesel using the in-situ transesterification method provides benefits in terms of time and energy so the process can be more effective and efficient. The yield obtained in this study was in the range of $13.51 \%-35.08 \%$ with the best yield of $35.08 \%$ in power usage and reaction time of 450 watts and 40 minutes respectively. After after optimization, using the response surface methodology with the type of face-centered central composite design is obtained that yield increased with increasing reaction time and microwave power with the best conditions of 50 minutes each and 440.53 watts with the highest yield reaching $35.72 \%$ (dry basis) through using of $\mathrm{KOH}$ catalysts with low concentrations, $2 \%$. The results of this study can be concluded that changes in reaction time and microwave power have a linear relationship to yield changes until they reach their optimum point.

\section{Acknowledgments}

This research is supported by research funding from the Directorate General of Research and Technology Strengthening Research and Development of Higher Education (RISTEK-DIKTI) of the Republic of Indonesia through the Higher Education Excellence Basic Research (PDUPT) scheme.

\section{References}

Akubude, V. C., Nwaigwe, K. N., and Dintwa, E. (2018). Production of bodiesel from microalgae via nanocatalyzed trans-esterification process: A review. Materials Science for Energy Technologies. 2, 216-225

Al-Ameri, M., and Al-Zuhair, S. (2019). Using switchable solvents for enhanced, simultaneous microalgae oil extractionreaction for biodiesel production. Biochemical Engineering Journal, 141, 217-224.

Ananyev, G., Carrieri, D., and Dismukes, G. C. (2008). Optimization of metabolic capacity and flux through environmental cues to maximize hydrogen production by the Cyanobacterium Arthrospira (Spirulina) maxima. Applied and Environmental Microbiology, 74(19), 6102-6113.

Bahadar, A., and Bilal Khan, M. (2013). Progress in energy from microalgae: A review. Renewable and Sustainable Energy Reviews, 27, 128-148.

Boldor, D., (2012) Microwave Transesterification. In Encyclopedia of Agricultural, Food, and Biological Engineering-2 Volume Set (Print Version) (pp. 1-7). CRC Press

Chisti, Y. (2007). Biodiesel from microalgae. Biotechnology Advances, 25(3), 294-306

Dai, Y. M., Chen, K. T., and Chen, C. C. (2014). Study of the microwave lipid extraction from microalgae for biodiesel production. Chemical Engineering Journal, 250, 267-273.

De Luna, M. D. G., Doliente, L. M. T., Ido, A. L., and Chung, T. W. (2017). In situ trans-esterification of Chlorella sp. microalgae using LiOH-pumice catalyst. Journal of Environmental Chemical Engineering, 5(3), 2830-2835.
Gude, V. G., Patil, P., Martinez-Guerra, E., and Deng, S. (2013). Microwave energy potential for biodiesel production. Sustainable Chemical Processes, 15, 1-31.

Kusuma H.S. and Mahfud, M. (2016). Response Surface Methodology for Optimization Studies of Microwaveassisted Extraction of Sandalwood Oil. J. Mater. Environ. Sci., 7(6), 1958-1971

Kalsum, U., Kusuma H.S., Roesyadi, A. and Mahfud, M., (2018). Production Biodiesel via In-situ Trans-esterification from Chlorella sp. using Microwave with Base Catalyst. Korean Chem. Eng. Res., 56(5), 773-778

Khan, S. A., Rashmi, Hussain, M. Z., Prasad, S., and Banerjee, U. C. (2009). Prospects of biodiesel production from microalgae in India. Renewable and Sustainable Energy Reviews, 13(9), 2361-2372. https://doi.org/10.1016/j.rser.2009.04.005

Mahfud, M., Suryanto, A., Qadariyah, L., Suprapto, S., and Kusuma, H. S. (2018). Production of Fatty Acid Methyl Ester from Microalgae Using Microwave: Kinetic of Transesterification Reaction Using $\mathrm{CaO}$ Catalyst. Korean Chem. Eng. Res., 56(2), 275-280.

Martinez-Guerra, E., and Gude, V. G. (2016). Alcohol effect on microwave-ultrasound enhanced trans-esterification reaction. Chemical Engineering and Processing: Process Intensification, 101, 1-7.

Martinez-Guerra, E., Gude, V. G., Mondala, A., Holmes, W., and Hernandez, R. (2014). Microwave and ultrasound enhanced extractive-trans-esterification of algal lipids. Applied Energy, 129, 354-363.

Patil, P. D., Gude, V. G., Mannarswamy, A., Cooke, P., MunsonMcGee, S., Nirmalakhandan, N., Lammers P., Deng, S. (2011). Optimization of microwave-assisted transesterification of dry algal biomass using response surface methodology. Bioresource Technology, 102(2), 1399-1405.

Prartono, T. R. I., Kawaroe, M., Sari, D. W., and Augustine, D. (2010). Fatty Acid Content of Indonesian Aquatic Microalgae. HAYATI Journal of Biosciences, 17(4), 196-200.

Quitain, A. T., Katoh, S., and Goto, M. (2011). MicrowaveAssisted Synthesis of Biofuels. Biofuel Production-Recent Developments and Prospects, 16, 415-. Armando T. Quitain, Shunsaku Katoh and Motonobu Goto (2011). MicrowaveAssisted Synthesis of Biofuels,Biofuel Production-Recent Developments and Prospects, Dr. Marco Aurelio Dos Santos Bernardes (Ed.), ISBN:978-953-307-478-8, InTech, Available from: http://www.intechopen com/ books/biofuel-productionrecent-developments-and-prospects/microwave-assistedsynthesis-of-biofuels

Ramesh, V., Narendrakumar, G., Thyagarajan, R., and Melchias, G. (2018). Biocatalysis and Agricultural Biotechnology A comparative analysis of biodiesel production and its properties from Leptolyngbya sp . BI-107 and Chlorella vulgaris under heat shock stress. Biocatalysis and Agricultural Biotechnology, 16, 502-506.

Velasquez-Orta, S. B., Lee, J. G. M., and Harvey, A. (2012). Alkaline in situ trans-esterification of Chlorella vulgaris. Fuel, 94, 544-550.

Zhang, Y., Li, Y., Zhang, X., and Tan, T. (2015). Biodiesel production by direct trans-esterification of microalgal biomass with co-solvent. Bioresource Technology, 196, 712715

This article is an extended version of a paper presented at International Conference of Process and Product Engineering (ICCPPE 2019) held on Sept 25, 2019. The article has been reviewed by journal peer-reviewers including complete proofs. 